\title{
Minimum QA Interval
}

National Cancer Institute

\section{Source}

National Cancer Institute. Minimum QA Interval. NCI Thesaurus. Code C120924.

The minimum time between the recording of a Q wave on ECG and the onset of the aortic blood pressure pulse. 